\title{
Missense variants in the TNFA epitopes and their effects on interaction with therapeutic antibodies-in silico analysis
}

Tamim Ahsan ${ }^{1}$ and Abu Ashfaqur Sajib²*

\begin{abstract}
Background: Tumor necrosis factor alpha (TNFA) is an important cytokine that influences multiple biological processes. It is one of the key mediators of acute and chronic systemic inflammatory reactions and plays a central role in several autoimmune diseases. A number of approved monoclonal antibodies (mAbs) are widely used to subside these autoimmune diseases. However, there is a high rate of non-responsiveness to treatments with these mAbs. Therefore, it is important to be able to predict responses of the patients in an individualistic manner to these therapeutic antibodies before administration. In the present study, we used in silico tools to explore the effects of missense variants in the respective epitopes of four therapeutic anti-TNFA mAbs_-adalimumab (ADA), certolizumab pegol (CZP), golimumab (GLM), and infliximab (IFX) —on their interactions with TNFA.

Results: The binding affinities of CZP and ADA to corresponding epitopes appear to be reduced by four (TNFA ${ }^{R 131 Q}$, TNFA $^{\mathrm{E} 135 \mathrm{G}}$, TNFA ${ }^{\mathrm{R} 138 \mathrm{Q}}$, and TNFA ${ }^{\mathrm{R} 138 \mathrm{~W}}$ ) and two (TNFA ${ }^{\mathrm{G} 66 \mathrm{C}}$ and TNFA ${ }^{\mathrm{G} 66 \mathrm{~S}}$ ) variants, respectively. The binding of GLM and IFX appears to be affected by TNFA ${ }^{\mathrm{R} 141 \mathrm{~S}}$ and TNFA ${ }^{\mathrm{R} 138 \mathrm{~W}}$, respectively. TNFA ${ }^{\mathrm{G} 66 \mathrm{C}}$ and TNFA ${ }^{\mathrm{G} 665}$ may be associated with autoimmune diseases, whereas TNFA ${ }^{E 135 G}$, TNFA ${ }^{\mathrm{R} 138 \mathrm{~W}}$, and TNFA ${ }^{\mathrm{R} 1415}$ may be pathogenic per se.
\end{abstract}

Conclusion: These variants may contribute to the observed inter-individual variability in response to anti-TNFA mAbs treatments and be used as markers to predict responses, and thus optimize therapeutic benefits to the patients.

Keywords: TNFA, Anti-TNFA antibody, Therapeutic antibody, Genetic variants, Autoimmune disease

\section{Background}

Tumor necrosis factor alpha (TNFA) is a cytokine that mediates pleotropic influences on a myriad of cellular processes including cell proliferation and differentiation, immune responses, apoptosis, necroptosis, etc [1, 2]. It is primarily produced as a type II transmembrane protein in stable homotrimeric arrangements, which is proteolytically cleaved into soluble cytokine (sTNF) by TNFAconverting enzyme (TACE) [3]. Its pleotropic actions are mediated through interaction with two distinct receptors-TNF receptor type 1 (TNFR1) and TNF receptor

\footnotetext{
*Correspondence: abu.sajib@du.ac.bd

2 Department of Genetic Engineering \& Biotechnology, University

of Dhaka, Dhaka 1000, Bangladesh

Full list of author information is available at the end of the article
}

type 2 (TNFR2) [4]. TNFR1, which is expressed in nearly all cells, is the major high-affinity TNFA receptor $[5,6]$. TNFR1-TNFA interaction primarily activates nuclear factor kappa B (NF-kB) and mitogen-activated protein kinase (MAPK) pathways and leads to proinflammatory responses, apoptosis, and necroptosis [1,7]. TNFR2 is expressed in $\mathrm{CD}^{+}$and $\mathrm{CD}^{+} \mathrm{T}$ lymphocytes, endothelial cells, microglia, oligodendrocytes, neurons, cardiac myocytes, thymocytes, and human mesenchymal stem cells [6]. TNFR2-TNFA interaction activates both classical and alternative NFKB pathways [7] and causes cell survival, cell expansion, angiogenesis, etc. [8, 9]. In addition to working independently, TNFR1 and TNFR2 can also engage in complex cross-talks to maintain a delicate balance between cell survival and apoptosis [10]. 
TNFA is one of the key mediators of acute and chronic systemic inflammatory reactions. TNFA induces its own secretion as well as the production of other inflammatory cytokines and chemokines, and thus plays a central role in several autoimmune diseases such as rheumatoid arthritis (RA), inflammatory bowel disease (IBD) including Crohn's disease (CD), ulcerative colitis (UC), multiple sclerosis (MS), systemic lupus erythematosus (SLE), systemic sclerosis, psoriasis (PS), psoriatic arthritis (PsA), and ankylosing spondylitis (AS) [11-13]. Modulation of inflammation by antibody-based inhibitors of receptorTNFA interactions leads to dramatic improvements in patients suffering from these autoimmune diseases [14]. Several FDA-approved anti-TNFA monoclonal antibodies (mAbs) such as adalimumab (ADA), certolizumab pegol (CZP), golimumab (GLM), and infliximab (IFX) are commercially available and widely used to treat such diseases [15].

ADA is a fully human anti-TNFA mAb [16], whereas CZP is composed of a humanized $F_{a b}$ fragment (50 kDa) of IgG1 isotype conjugated to a $40-\mathrm{kDa}$ polyethylene glycol (PEG) moiety [17]. GLM is a human IgG1 mAb, which was originally produced in transgenic mice immunized with human TNFA, but is commercially produced in a recombinant cell line [18]. IFX is a chimeric monoclonal IgG1 antibody with human constant and murine variable regions [19]. ADA, CZP, GLM, and IFX bind to sites on TNFA that overlap with its sites of interaction with the receptor [20-23].

ADA, CZP, GLM, and IFX are widely prescribed to treat RA, CD, UC, PS, PsA, and AS. In fact, ADA and IFX are among the top-selling therapeutic mAbs [24]. These protein-based therapeutics are quite expensive $[25,26]$. However, their clinical efficacy is sometimes limited due to a high rate $(30-40 \%)$ of non-responsiveness [27, 28]. Hence, it is important to be able to predict responses of the patients in an individualistic manner to these therapeutic antibodies before administering them. To the best of our knowledge, no single-nucleotide polymorphism (SNP) or variant in TNFA epitopes has been associated with responses to corresponding mAbs. In this study, we investigated the interactions of ADA, CZP, GLM, and IFX mAbs with their respective epitopic variants in TNFA using in silico tools.

\section{Methods}

\section{Missense variants in the epitopes for anti-TNFA monoclonal antibodies}

The amino acid residues of TNFA that constitute the epitopes for ADA, CZP, GLM, and IFX were retrieved through literature search [20-23]. Missense variants within the TNFA epitopes were obtained using the Ensembl Genome Browser [29].

\section{Prediction of the effects of missense variants on TNFA-mAb interactions}

X-ray crystallographic structures of TNFA-ADA (PDB ID: 3WD5), TNFA-CZP (PDB ID: 5WUX), TNFA-GLM (PDB ID: 5YOY), and TNFA-IFX (PDB ID: 4G3Y) complexes were retrieved from the Protein Data Bank (PDB) [30]. Since 3WD5 and 4G3Y contained a single light and a heavy chain of the antibody with a single epitope, these complexes were not customized any further. 5WUX and $5 Y O Y$ contain complex structures with multiple epitopes and heavy and light chains, and therefore required customization for analysis. H (CZP heavy chain), L (CZP light chain), and E (TNFA molecule) chains from TNFACZP, and I (GLM heavy chain), F (GLM light chain), and A (TNFA molecule) chains from TNFA-GLM X-ray crystallographic structures were retained for further analysis. The rest of the chains were removed using UCSF Chimera 1.14 [31] to retain interactions between a single antibody molecule and a single TNFA protomer. These four structures of antigen-antibody complexes were used as inputs to predict the effects of the epitopic missense variants on interaction with the relevant antibodies using mCSM-PPI2 [32], SAAMBE-3D [33], and MutaBind [34].

\section{D modeling and stabilizing energy calculation of TNFA variant-mAb complexes}

The amino acid sequence of TNFA (UniProt accession number: P01375) was retrieved from UniProt [35]. Deletion of the signal peptide (first 76 residues) and substitution of residues at the variant sites was performed manually. Amino acid sequences of the heavy and light chains of the mAbs were obtained from the Therapeutic Structural Antibody Database (TheraSAbDab) [36]. 3D models of TNFA-mAb complexes were generated using template-based modeling in SWISS-MODEL [37]. X-ray crystallographic structures of the four TNFA-mAb complexes (previously mentioned) were used as templates. Chains in the models were renamed (wherever applicable) to $\mathrm{H}$ (mAb heavy chain), L (mAb light chain), and A (TNFA molecule) using UCSF Chimera 1.14 [31]. Stabilizing energies of TNFA-mAb complexes were calculated using the PPCheck web server [38].

\section{Analyses of structures, interfaces, and interactions}

Changes in the TNFA structure due to the variants were predicted using Missense3D [39]. 2D maps of interactions between TNFA and $\mathrm{H}$ and $\mathrm{L}$ chains of mAbs were generated with iCn3D using the default parameters [40]. Distances between selected atoms and areas of interacting surfaces between TNFA and mAb 
chains were measured using UCSF Chimera 1.14 [31] and $\mathrm{iCn} 3 \mathrm{D}$ [40], respectively. The number of bonds and interactions (van der Waals interactions, $\mathrm{H}$-bonds, weak $\mathrm{H}$-bonds, and ionic interactions) between TNFA and $\mathrm{mAb}$ chains was calculated with Arpeggio-a web server for calculating interatomic interactions in protein structures [41]. Antigen-antibody interfaces were visualized using PyMOL [42]. In all cases, 3D models of TNFA-mAb complexes were used as the inputs.

\section{Prediction of the variants' effects on TNFA-receptor interactions}

To assess whether the variants predicted to significantly affect the TNFA-mAb interactions would also affect interactions between TNFA and its receptors, $\mathrm{X}$-ray crystallographic structure of the TNFA-TNFR2 complex (PDB ID: 3ALQ) was retrieved from the PDB [30]. The PDB file contained multiple TNFA and TNFR2 chains. Therefore, the structure was customized by keeping only chain $\mathrm{A}$ and removing all the other chains using UCSF Chimera 1.14 [31]. TNFATNFR2 interactions were checked using iCn3D [40]. Only two chains ( $R$ and $T$ ) of TNFR2 were found to form bonds with the selected TNFA chain. So, these two chains were retained and the other chains were deleted. The PDB file thus prepared was used as an input in mCSM-PPI2 [32], SAAMBE-3D [33], and MutaBind2 [43] to assess the effects of selected missense variants on TNFA-TNFR2 interactions. We could not retrieve any X-ray crystallographic structure of TNFA-TNFR1 complex.

\section{Assessment of pathogenicity of the variants}

DisGeNET [44] and PhenoScanner V2 [45] databases were searched for diseases associated with the selected variants. PolyPhen2- and SIFT-predicted pathogenicity-associated information of these selected variants were retrieved from Ensembl Genome Browser [29]. Pathogenicity was also predicted using PMut [46], Meta-SNP [47], and PredictSNP 1.0 [48].

\section{Results}

Missense variants in the epitopes of anti-TNFA monoclonal antibodies

Amino acid residues that constitute the epitopes of TNFA for ADA [20], CZP [21], GLM [22], and IFX [23] were retrieved through literature survey (Table 1). Based on the data collected via Ensembl, eleven missense variants were found in each of the epitopes for ADA and CZP (Tables 2 and 3). Seven and ten missense variants were found in the epitopes for GLM and IFX, respectively (Tables 4 and 5).

\section{Binding affinities of TNFA epitopic variants to anti-TNFA therapeutic antibodies}

The effects of the identified missense variants on TNFA$\mathrm{mAb}$ interactions were predicted in two different ways. First, changes in the binding affinity $\left(\Delta \Delta G=\Delta G_{\text {mutant }}\right.$ $\left.-\Delta G_{\text {wild-type }}\right)$ were predicted using the crystallographic structures with mCSM-PPI2 [32], SAAMBE-3D [33], and MutaBind [34]. Second, the 3D models of TNFA$\mathrm{mAb}$ complexes (both wild-type and epitopic variants of TNFA) were generated and total stabilizing energies of the complexes were determined using PPCheck [38]. In all cases, $\Delta \Delta G$ values of $>1.0 \mathrm{kcal} / \mathrm{mol}(4.18 \mathrm{~kJ} / \mathrm{mol})$ were considered to be a significant reduction in binding affinity [49]. In case of antigen-antibody interactions, $|\Delta \Delta G|$ $>1.0 \mathrm{kcal} / \mathrm{mol}$ may be considered as an indication of significant changes in antibody binding affinity [50].

None of the variants was predicted by every tool to reduce the binding affinity of ADA to TNFA by more than $1.0 \mathrm{kcal} /$ mol (Table 2). Only the mCSM-PPI2 and MutaBind predicted values of $\Delta \Delta \mathrm{G}$ due for TNFA ${ }^{\mathrm{G} 66 \mathrm{C}}$ and TNFA ${ }^{\mathrm{G} 66 \mathrm{~S}}$ (rs1454071630) variants were $>1.0 \mathrm{kcal} / \mathrm{mol}$. Since $\Delta \Delta \mathrm{G}$ values predicted by SAAMBE-3D were very close to 0.53 $\mathrm{kcal} / \mathrm{mol}$ [33] in both cases, TNFA ${ }^{\mathrm{G} 66 \mathrm{C}}$ and TNFA ${ }^{\mathrm{G} 66 \mathrm{~S}}$ might actually destabilize the TNFA-ADA complex. PPcheck predicted interactions between these epitopic variants of TNFA with the L chain of ADA were weaker as well. Although MutaBind predicted weaker interactions of these variants with both $\mathrm{L}$ and $\mathrm{H}$ chains of ADA, binding to the $\mathrm{L}$ chain was more severely affected $(\Delta \Delta \mathrm{G}>2.3 \mathrm{kcal} / \mathrm{mol})$ than that of the $\mathrm{H}$ chain $(\Delta \Delta \mathrm{G} \approx 1.6 \mathrm{kcal} / \mathrm{mol})$.

Table 1 Epitopes of TNFA for adalimumab, certolizumab pegol, golimumab and infliximab

\begin{tabular}{|c|c|c|}
\hline Antibody & TNFA epitopes & References \\
\hline Adalimumab & $\begin{array}{l}\text { Pro-19, Gln-20, Glu-23, Lys-65 To Gln-67, Glu-10 TO Pro-113, Tyr-141, Ala-145, Glu-146, Thr-71, His-72, Thr-77, Thr-79, Ser-81, } \\
\text { Lys-89 To Asn-91, Glu-135 To Asn-137 }\end{array}$ & {$[20]$} \\
\hline Certolizumab & $\begin{array}{l}\text { Gly-24, Asp-45, Gln-47, Thr-77, Ile-83, Val-85, Ser-86, Gln-88, Thr-89, Lys-90, Arg-131, Glu-135, Asn-137, Arg-138, Pro-139, } \\
\text { Asp-140 }\end{array}$ & {$[21]$} \\
\hline Golimumab & Gly-24, Lys-65, Gln-67, Ser-71, Glu-104, Thr-105, Pro-106, Glu-107, Gly-108, Ala-111, Arg-138, Asp-140, Tyr-141 & {$[22]$} \\
\hline Infliximab & Gln-67, Pro-70, Ser-71, His-73, Gln-102, Thr-105, Glu-107, Ala-109, Glu-110, Arg-138, Asn-137, Tyr-141 & {$[24]$} \\
\hline
\end{tabular}


Table 2 Effects of epitopic missense variants on TNFA-adalimumab interaction

\begin{tabular}{|c|c|c|c|c|c|c|c|c|}
\hline \multirow[t]{2}{*}{ SNP_ID } & \multirow{2}{*}{$\begin{array}{l}\text { Amino acid } \\
\text { position }^{\mathrm{a}}\end{array}$} & \multirow{2}{*}{$\begin{array}{l}\text { Amino acid } \\
\text { change }\end{array}$} & \multicolumn{3}{|c|}{$\Delta \Delta \mathrm{G}(\mathrm{Kcal} / \mathrm{mol})^{\mathrm{b}}$} & \multirow{2}{*}{$\begin{array}{l}\text { Antibody } \\
\text { chains }\end{array}$} & \multirow{2}{*}{$\begin{array}{l}\text { MutaBind }^{\text {b }} \\
\Delta \Delta \mathrm{G}(\mathrm{kcal} / \mathrm{mol})\end{array}$} & \multirow{2}{*}{$\begin{array}{l}\text { PPcheck } \\
\text { Total stabilizing } \\
\text { energy }(\mathrm{kJ} / \mathrm{mol})\end{array}$} \\
\hline & & & mCSM-PPI2 & SAAMBE-3D & MutaBind & & & \\
\hline \multirow[t]{2}{*}{ WT } & - & - & - & - & - & $\mathrm{H}$ & - & -58.31 \\
\hline & - & - & - & - & - & $L$ & - & -222.88 \\
\hline \multirow[t]{2}{*}{ rs1454071630 } & 66 & $G>C$ & 1.345 & 0.38 & 1.94 & $\mathrm{H}$ & 1.65 & -58.09 \\
\hline & - & - & - & - & - & $\mathrm{L}$ & 2.33 & -208.55 \\
\hline \multirow[t]{2}{*}{ rs 1454071630} & 66 & $G>S$ & 1.279 & 0.45 & 2 & $\mathrm{H}$ & 1.6 & -58.05 \\
\hline & - & - & - & - & - & L & 2.38 & -207.41 \\
\hline \multirow[t]{2}{*}{ rs552363141 } & 72 & $\mathrm{~T}>\mathrm{N}$ & 0.116 & 0.15 & 0.12 & $\mathrm{H}$ & 0.7 & -58.33 \\
\hline & - & - & - & - & - & $L$ & 0.46 & -222.89 \\
\hline \multirow[t]{2}{*}{ rs946653352 } & 72 & $\mathrm{~T}>\mathrm{P}$ & 0.107 & 0.19 & 0.64 & $\mathrm{H}$ & 1.35 & -58.32 \\
\hline & - & - & - & - & - & $L$ & 1.23 & -222.89 \\
\hline \multirow[t]{2}{*}{ rs758652888 } & 73 & $\mathrm{H}>\mathrm{Q}$ & 0.373 & 0.36 & 0.13 & $\mathrm{H}$ & 0.9 & -58.33 \\
\hline & - & - & - & - & - & $L$ & 0.63 & -222.93 \\
\hline \multirow[t]{2}{*}{ rs753130938 } & 73 & $H>R$ & 0.101 & 0.25 & 0.21 & $\mathrm{H}$ & 0.94 & -58.33 \\
\hline & - & - & - & - & - & L & 0.66 & -222.93 \\
\hline \multirow[t]{2}{*}{ rs1473587140 } & 110 & $E>K$ & 0.17 & 1.64 & 0.86 & $\mathrm{H}$ & 1.23 & -58.13 \\
\hline & - & - & - & - & - & L & 1.19 & -225.92 \\
\hline \multirow[t]{2}{*}{ rs760036765 } & 111 & $A>T$ & -0.272 & 0.21 & 0.97 & $\mathrm{H}$ & 0.96 & -58.25 \\
\hline & - & - & - & - & - & $L$ & 1.16 & -225.75 \\
\hline \multirow[t]{2}{*}{ rs7775455571 } & 135 & $E>G$ & 0.235 & 0.59 & 0.48 & $\mathrm{H}$ & 1.22 & -58.53 \\
\hline & - & - & - & - & - & $L$ & 1.03 & -229.29 \\
\hline \multirow[t]{2}{*}{ rs758189183 } & 135 & $E>K$ & 0.048 & 0.55 & 0.3 & $\mathrm{H}$ & 1.03 & -58.47 \\
\hline & - & - & - & - & - & $L$ & 0.84 & -227.42 \\
\hline \multirow[t]{2}{*}{ rs763621932 } & 141 & $Y>S$ & 0.28 & 1.07 & 1.02 & $\mathrm{H}$ & 1.16 & -58.3 \\
\hline & - & - & - & - & - & $\mathrm{L}$ & 1.3 & -217.37 \\
\hline
\end{tabular}

${ }^{\mathrm{a}}$ Amino acid positions were calculated excluding the signal peptide (76 amino acids)

${ }^{\mathrm{b}}$ Positive values of $\Delta \Delta \mathrm{G}$ indicate decreasing affinity

Epitopes with TNFA ${ }^{\mathrm{R} 131 \mathrm{Q}}$ (rs376368223), TNFA ${ }^{\mathrm{E} 135 \mathrm{G}}$ (rs777545571), TNFA ${ }^{\mathrm{R} 138 \mathrm{Q}}$ (rs770509340), and $\mathrm{TNFA}^{\mathrm{R} 138 \mathrm{~W}}$ (rs141307820) variants were predicted to have weaker interactions with CZP, although none of the variants was predicted to significantly decrease $(\Delta \Delta \mathrm{G}>1.0 \mathrm{kcal} / \mathrm{mol})$ by all the tools (Table 3). Although mCSM-PPI2, SAAMBE-3D, and MutaBind predicted destabilizing effect of TNFA ${ }^{\text {E135k }}$ (rs758189183) on interaction with CZP, this finding was not corroborated with the 3D model. TNFA ${ }^{\mathrm{R} 131 \mathrm{Q}}$ weakened the interactions between TNFA and the $\mathrm{H}$ chain of CZP. On the other hand, TNFA ${ }^{\mathrm{E} 135 \mathrm{G}}$, TNFA ${ }^{\mathrm{R} 138 \mathrm{Q}}$, and TNFA $^{\mathrm{R} 138 \mathrm{~W}}$ weakened interactions between TNFA and the $\mathrm{L}$ chain of CZP.

Significant reduction in affinity $(\Delta \Delta \mathrm{G}>1.0 \mathrm{kcal} / \mathrm{mol})$ of GLM for its TNFA epitope was convincingly predicted to be caused due to the TNFA ${ }^{\mathrm{Y} 141 \mathrm{~S}}$ (rs763621932) variant by all the tools used in this study (Table 4). Both MutaBind and PPCheck predicted weaker interactions between TNFA $^{\mathrm{Y} 141 \mathrm{~S}}$ and the $\mathrm{H}$ chain of GLM.
mCSM-PPI2, SAAMBE-3D, and MutaBind predicted significantly weakened interaction $(\Delta \Delta \mathrm{G}>1.0 \mathrm{kcal} / \mathrm{mol})$ between TNFA $^{\mathrm{R} 138 \mathrm{~W}}$ (rs141307820) variant and IFX (Table 5). But the effect could not be replicated with 3D modeling.

\section{Effects of epitopic variants on TNFA structure} and interaction with anti-TNFA antibodies and TNFR2

In TNFA ${ }^{\mathrm{WT}}$, the Glu23 residue was not in contact (cutoff value 4) with Asp1 residue in the L chain of ADA (Fig. 1A). The distance between Glu23 in TNFA (OE1) and Asp1 residue in the L chain was $4.065 \AA$ (Fig. 1D). But both TNFA ${ }^{\mathrm{G} 66 \mathrm{C}}$ and TNFA ${ }^{\mathrm{G} 66 \mathrm{~S}}$ variants changed the conformation and brought those two residues in contact with one another by reducing the distance to $<3.9 \AA$ (Fig. 1B, 1C, 1E and 1F). TNFA ${ }^{\mathrm{G} 66 \mathrm{C}}$ and TNFA ${ }^{\mathrm{G} 66 \mathrm{~S}}$ variants also caused structural changes in TNFA by expanding the cavity (surface pocket) by $>70 \AA^{3}$ (Table 6). Furthermore, these two variants increased the buried surface area between TNFA and the L chain of ADA by 
Table 3 Effects of epitopic missense variants on TNFA-certolizumab pegol interaction

\begin{tabular}{|c|c|c|c|c|c|c|c|c|}
\hline \multirow[t]{2}{*}{ SNP_ID } & \multirow{2}{*}{$\begin{array}{l}\text { Amino acid } \\
\text { position }^{\mathrm{a}}\end{array}$} & \multirow{2}{*}{$\begin{array}{l}\text { Amino acid } \\
\text { change }\end{array}$} & \multicolumn{3}{|c|}{$\Delta \Delta \mathrm{G}(\mathrm{Kcal} / \mathrm{mol})^{\mathrm{b}}$} & \multirow{2}{*}{$\begin{array}{l}\text { Antibody } \\
\text { chains }\end{array}$} & \multirow{2}{*}{$\begin{array}{l}\text { MutaBind }^{\text {b }} \\
\Delta \Delta \mathrm{G}(\mathrm{kcal} / \mathrm{mol})\end{array}$} & \multirow{2}{*}{$\begin{array}{l}\text { PPcheck } \\
\text { Total stabilizing } \\
\text { energy }(\mathrm{kJ} / \mathrm{mol})\end{array}$} \\
\hline & & & mCSM-PPI2 & SAAMBE-3D & MutaBind & & & \\
\hline \multirow[t]{2}{*}{ WT } & - & - & - & - & - & $\mathrm{H}$ & - & -269.69 \\
\hline & - & - & - & - & - & L & - & -152.18 \\
\hline \multirow[t]{2}{*}{ rs1298153213 } & 45 & $\mathrm{D}>\mathrm{N}$ & -0.619 & 0.95 & 0.61 & $\mathrm{H}$ & 0.98 & -277.93 \\
\hline & - & - & - & - & - & L & 0.46 & -152.11 \\
\hline \multirow[t]{2}{*}{ rs373646181 } & 85 & $V>F$ & -1.58 & 0.01 & 0.7 & $\mathrm{H}$ & 0.97 & -271.68 \\
\hline & - & - & - & - & - & L & 0.54 & -152.18 \\
\hline \multirow[t]{2}{*}{ rs778731236 } & 85 & $V>G$ & 0.416 & 1.55 & 0.99 & $\mathrm{H}$ & 1.08 & -266.54 \\
\hline & - & - & - & - & - & L & 0.47 & -152.18 \\
\hline \multirow[t]{2}{*}{ rs373646181 } & 85 & $V>1$ & 0.339 & 0.53 & 0.79 & $\mathrm{H}$ & 1.01 & -274.09 \\
\hline & - & - & - & - & - & L & 0.48 & -152.17 \\
\hline \multirow[t]{2}{*}{ rs376368223 } & 131 & $R>Q$ & -0.078 & 0.94 & 2.31 & $\mathrm{H}$ & 2.52 & -236.86 \\
\hline & - & - & - & - & - & L & 0.57 & -152.06 \\
\hline \multirow[t]{2}{*}{ rs777545571 } & 135 & $E>G$ & 0.784 & 0.67 & 2.25 & $\mathrm{H}$ & 1.03 & -269.49 \\
\hline & - & - & - & - & - & L & 1.98 & -145.12 \\
\hline \multirow[t]{2}{*}{ rs758189183 } & 135 & $E>K$ & 1.119 & 0.67 & 1.86 & $\mathrm{H}$ & 0.92 & -279.21 \\
\hline & - & - & - & - & - & L & 1.74 & -157.25 \\
\hline \multirow[t]{2}{*}{ rs770509340 } & 138 & $\mathrm{R}>\mathrm{Q}$ & 0.026 & 2.25 & 1.77 & $\mathrm{H}$ & 0.41 & -269.36 \\
\hline & - & - & - & - & - & L & 1.96 & -120.82 \\
\hline \multirow[t]{2}{*}{ rs141307820 } & 138 & $R>W$ & 0.652 & 1.53 & 2.19 & $\mathrm{H}$ & 0.51 & -269.49 \\
\hline & - & - & - & - & - & L & 2.42 & -142.18 \\
\hline \multirow[t]{2}{*}{ rs370893734 } & 140 & $\mathrm{D}>\mathrm{N}$ & 0.64 & 0.75 & 0.64 & $\mathrm{H}$ & 0.42 & -269.56 \\
\hline & - & - & - & - & - & L & 0.88 & -147.77 \\
\hline \multirow[t]{2}{*}{ rs370893734 } & 140 & $D>Y$ & -0.122 & 0.25 & 0.92 & $\mathrm{H}$ & 0.74 & -269.58 \\
\hline & - & - & - & - & - & L & 1.21 & -149.7 \\
\hline
\end{tabular}

${ }^{\mathrm{a}}$ Amino acid positions were calculated excluding the signal peptide (76 amino acids)

${ }^{\text {b }}$ Positive values of $\Delta \Delta G$ indicate decreasing affinity

$>100 \AA^{2}$ compared to the wild-type complex, although the rest of the surface area of these two chains remained similar (Table 6). Additionally, alterations in the antigen-antibody interface region were observed in the case of these two variants (Fig. 2). These structural changes affected interactions between TNFA and the L chain of ADA mainly through the loss or weakening of van der Waals interactions and $\mathrm{H}$-bonds.

Change in TNFA structure or interaction at the TNFACZP interface was not caused by any of the four variants (TNFA $^{\mathrm{R} 131 \mathrm{Q}}, \mathrm{TNFA}^{\mathrm{E} 135 \mathrm{G}}$, TNFA ${ }^{\mathrm{R} 138 \mathrm{Q}}$, and $\mathrm{TNFA}^{\mathrm{R} 138 \mathrm{~W}}$ ) that were predicted by $\mathrm{mCSM}-\mathrm{PPI} 2$, SAAMBE-3D, and MutaBind to destabilize the complex (Table 6). The ionic interaction between Arg131 in TNFA and Asp31 in the $\mathrm{H}$ chain of CZP was lost due to TNFA ${ }^{\mathrm{R} 131 \mathrm{Q}}$ (Fig. 3A and B). This loss of interaction caused structural changes in the antigen-antibody interface region (Fig. 4B). The H-bond between Glu135 of TNFA and Tyr49 in the L chain of CZP was lost in the presence of TNFA ${ }^{\mathrm{E} 135 \mathrm{G}}$ (Fig. 3C and D). Both TNFA ${ }^{\mathrm{R} 138 \mathrm{Q}}$ and TNFA ${ }^{\mathrm{R} 138 \mathrm{~W}}$ caused the loss of H-bond between Arg138 of TNFA and Tyr60 in the L chain of CZP (Fig. 3E and F). These H-bond losses changed patterns of interacting residues in the CZP L chain (Fig. 4E and F).

None of the TNFA ${ }^{\mathrm{Y} 141 \mathrm{~S}}$ and $\mathrm{TNFA}^{\mathrm{R} 138 \mathrm{~W}}$ variants caused any changes in TNFA structure or the interfaces of TNFA-GLM $\mathrm{H}$ chain and TNFA-IFX L chain, respectively (Table 6). TNFA ${ }^{\text {Y141S }}$ caused the loss of the H-bond between Tyr141 of TNFA and Tyr111 in the H chain of GLM (Fig. 5A and B). TNFA ${ }^{\mathrm{R} 138 \mathrm{~W}}$ caused the loss of cation-pi interaction between Arg138 of TNFA and Phe96 in the L chain of IFX (Fig. 5C and D). These alterations however did not cause any noticeable changes at antigenantibody interfaces (Fig. 6).

None of the seven variants $\left(\mathrm{TNFA}^{\mathrm{G} 66 \mathrm{C}}\right.$, TNFA ${ }^{\mathrm{G} 66 \mathrm{~S}}$, $\mathrm{TNFA}^{\mathrm{R} 131 \mathrm{Q}}, \mathrm{TNFA}^{\mathrm{E} 135 \mathrm{G}}, \mathrm{TNFA}^{\mathrm{R} 138 \mathrm{Q}}, \mathrm{TNFA}^{\mathrm{R} 138 \mathrm{~W}}$, and TNFA $^{\mathrm{Y} 141 \mathrm{~S}}$ ), that were predicted to have substantial destabilizing effects on TNFA-mAb interactions, 
Table 4 Effects of epitopic missense variants on TNFA-golimumab interaction

\begin{tabular}{|c|c|c|c|c|c|c|c|c|}
\hline \multirow[t]{2}{*}{ SNP_ID } & \multirow{2}{*}{$\begin{array}{l}\text { Amino acid } \\
\text { position }^{\mathrm{a}}\end{array}$} & \multirow{2}{*}{$\begin{array}{l}\text { Amino acid } \\
\text { change }\end{array}$} & \multicolumn{3}{|c|}{$\Delta \Delta \mathrm{G}(\mathrm{Kcal} / \mathrm{mol})^{\mathrm{b}}$} & \multirow{2}{*}{$\begin{array}{l}\text { Antibody } \\
\text { chains }\end{array}$} & \multirow{2}{*}{$\begin{array}{l}\text { MutaBind }^{\mathrm{b}} \\
\Delta \Delta \mathrm{G}(\mathrm{kcal} / \mathrm{mol})\end{array}$} & \multirow{2}{*}{$\begin{array}{l}\text { PPcheck } \\
\text { Total stabilizing } \\
\text { energy }(\mathrm{kJ} / \mathrm{mol})\end{array}$} \\
\hline & & & mCSM-PPI2 & SAAMBE-3D & MutaBind & & & \\
\hline \multirow[t]{2}{*}{ WT } & - & - & - & - & - & $\mathrm{H}$ & - & -290.62 \\
\hline & - & - & - & - & - & L & - & -55.79 \\
\hline \multirow[t]{2}{*}{ rs140654183 } & 105 & $\mathrm{~T} / \mathrm{N}$ & 0.463 & 0.67 & 0.84 & $\mathrm{H}$ & 0.58 & -294.29 \\
\hline & - & - & - & - & - & L & 0.98 & -56.15 \\
\hline \multirow[t]{2}{*}{ rs760036765 } & 111 & $\mathrm{~A} / \mathrm{T}$ & -0.711 & 0.54 & 1.35 & $\mathrm{H}$ & 1.62 & -300.47 \\
\hline & - & - & - & - & - & L & 1.01 & -55.71 \\
\hline \multirow[t]{2}{*}{ rs770509340 } & 138 & $\mathrm{R} / \mathrm{Q}$ & 0.075 & 1.47 & 0.49 & $\mathrm{H}$ & 0.25 & -284.33 \\
\hline & - & - & - & - & - & L & 0.96 & -54.37 \\
\hline \multirow[t]{2}{*}{ rs141307820 } & 138 & $\mathrm{R} / \mathrm{W}$ & 0.668 & 1.03 & 0.72 & $\mathrm{H}$ & 0.44 & -285.08 \\
\hline & - & - & - & - & - & L & 1.23 & -55.81 \\
\hline \multirow[t]{2}{*}{ rs370893734 } & 140 & $\mathrm{D} / \mathrm{N}$ & 1.279 & 0.96 & 2.4 & $\mathrm{H}$ & 0.75 & -293.72 \\
\hline & - & - & - & - & - & L & 1.41 & -62.05 \\
\hline \multirow[t]{2}{*}{ rs370893734 } & 140 & $\mathrm{D} / \mathrm{Y}$ & 0.213 & 0.78 & 4 & $\mathrm{H}$ & 1.01 & -285.94 \\
\hline & - & - & - & - & - & L & 1.42 & -53.07 \\
\hline \multirow[t]{2}{*}{ rs763621932 } & 141 & $Y / S$ & 2.219 & 1.34 & 2.45 & $\mathrm{H}$ & 2.07 & -270.91 \\
\hline & - & - & - & - & - & L & 1.43 & -55.23 \\
\hline
\end{tabular}

${ }^{a}$ Amino acid positions were calculated excluding the signal peptide (76 amino acids)

${ }^{\mathrm{b}}$ Positive values of $\Delta \Delta \mathrm{G}$ indicate decreasing affinity

appeared to significantly destabilize TNFA-TNFR2 interactions unanimously by all the tools used in the analysis (Supplementary Table 1).

\section{Pathogenicity of the variants}

Based on the data retrieved from DisGeNET and PhenoScanner databases, rs1454071630 (TNFA ${ }^{\mathrm{G} 66 \mathrm{C}}$ and $\mathrm{TNFA}^{\mathrm{G} 66 \mathrm{~S}}$ ) is associated with generalized pustular psoriasis [51]. No other variant among the seven selected ones has been associated with any disease yet. But along with TNFA ${ }^{\mathrm{G} 66 \mathrm{C}}$ and TNFA ${ }^{\mathrm{G} 66 \mathrm{~S}}$, TNFA ${ }^{\mathrm{E} 135 \mathrm{G}}$ was also predicted to have deleterious effects by all of the predictive tools (Table 7). Multiple tools predicted the TNFA ${ }^{\mathrm{R} 138 \mathrm{~W}}$ and TNFA ${ }^{\mathrm{Y} 141 \mathrm{~S}}$ variants to be disease-causing, whereas all tools used in this study predicted TNFA ${ }^{\mathrm{R} 131 \mathrm{Q}}$ and $\mathrm{TNFA}^{\mathrm{R} 138 \mathrm{Q}}$ to be non-pathogenic.

\section{Discussion}

The aim of this study was to investigate the effects of epitopic missense variants in TNFA on interaction with corresponding therapeutic anti-TNFA antibodies and identify the candidate variants that may be an important predictor of responsiveness to these antibodies. In order to do so, the effects of those variants on the binding affinity of ADA, CZP, GLM, and IFX to TNFA were predicted using mCSM-PPI2, SAAMBE-3D, and MutaBind. These tools use different methods to predict $\Delta \Delta$ G. mCSM-PPI2 is a machine learning method that utilizes graph-based structural signatures known as mCSM [32]. These signatures encode distance patterns between atoms and can represent the protein residue environment and are used to train predictive models [52]. SAAMBE-3D is a development of the SAAMBE method, which uses the molecular mechanics/Poisson Boltzmann surface area (MM/ PBSA) and knowledge-based terms to predict $\Delta \Delta G$ and amino acid-specific dielectric constant to mimic mutation-induced conformational flexibility [33]. MutaBind method uses molecular mechanics force fields, statistical potentials, and fast side-chain optimization algorithms [34]. Tools that use different methods may yield conflicting results, but their combined usage can help clarify the impacts of mutations [53]. The predicted destabilizing effects in our study were also assessed using 3D models of TNFA-mAb complexes. Variants that were predicted to substantially destabilize the TNFA-mAb interactions were selected for further analyses such as prediction of changes in TNFA structures and TNFA-mAb interfaces and calculation of van der Waals interactions, $\mathrm{H}$-bonds, weak $\mathrm{H}$-bonds, and ionic interactions because of their importance in antigen-antibody interactions [54]. Although none of these tools is supposed to be $100 \%$ accurate, we minimized the chances of erroneous predictions by using multiple tools and making consensus decisions. Direct experimental methods may provide more accurate results, but the use of in silicotools to prioritize the candidate variants may save time and effort [55]. 
Table 5 Effects of epitopic missense variants on TNFA-infliximab interaction

\begin{tabular}{|c|c|c|c|c|c|c|c|c|}
\hline \multirow[t]{2}{*}{ SNP_ID } & \multirow{2}{*}{$\begin{array}{l}\text { Amino acid } \\
\text { position }^{\mathrm{a}}\end{array}$} & \multirow{2}{*}{$\begin{array}{l}\text { Amino acid } \\
\text { change }\end{array}$} & \multicolumn{3}{|c|}{$\Delta \Delta \mathrm{G}(\mathrm{Kcal} / \mathrm{mol})^{\mathrm{b}}$} & \multirow{2}{*}{$\begin{array}{l}\text { Antibody } \\
\text { chains }\end{array}$} & \multirow{2}{*}{$\begin{array}{l}\text { MutaBind }^{\mathrm{b}} \\
\Delta \Delta \mathrm{G}(\mathrm{kcal} / \mathrm{mol})\end{array}$} & \multirow{2}{*}{$\begin{array}{l}\text { PPcheck } \\
\text { Total stabilizing } \\
\text { energy }(\mathrm{kJ} / \mathrm{mol})\end{array}$} \\
\hline & & & mCSM-PPI2 & SAAMBE-3D & MutaBind & & & \\
\hline \multirow[t]{2}{*}{ WT } & - & - & - & - & - & $\mathrm{H}$ & - & -188.42 \\
\hline & - & - & - & - & - & $L$ & - & -148.55 \\
\hline \multirow[t]{2}{*}{ rs1427914441 } & 70 & $\mathrm{P} / \mathrm{S}$ & 0.669 & 1.05 & 0.6 & $\mathrm{H}$ & 1.18 & -180.87 \\
\hline & - & - & - & - & - & $L$ & 0.31 & -148.18 \\
\hline \multirow[t]{2}{*}{ rs758652888 } & 73 & $\mathrm{H} / \mathrm{Q}$ & 0.264 & 1.03 & 0.18 & $\mathrm{H}$ & 0.47 & -188.4 \\
\hline & - & - & - & - & - & L & 1.41 & -137.66 \\
\hline \multirow[t]{2}{*}{ rs753130938 } & 73 & $H / R$ & 0.034 & 0.84 & 0.31 & $\mathrm{H}$ & 0.53 & -188.38 \\
\hline & - & - & - & - & - & L & 1.45 & -145.3 \\
\hline \multirow[t]{2}{*}{ rs140654183 } & 105 & $\mathrm{~T} / \mathrm{N}$ & 0.315 & 0.62 & -0.1 & $\mathrm{H}$ & 1.09 & -186.46 \\
\hline & - & - & - & - & - & L & 0.66 & -148.51 \\
\hline \multirow[t]{2}{*}{ rs1473587140 } & 110 & $E / K$ & 0.491 & 1 & 0.17 & $\mathrm{H}$ & 1.18 & -184.14 \\
\hline & - & - & - & - & - & L & 0.63 & -148.55 \\
\hline \multirow[t]{2}{*}{ rs770509340 } & 138 & $\mathrm{R} / \mathrm{Q}$ & 0.875 & 1.81 & 1.2 & $\mathrm{H}$ & 0.72 & -186.64 \\
\hline & - & - & - & - & - & L & 1.56 & -146.21 \\
\hline \multirow[t]{2}{*}{ rs141307820 } & 138 & $\mathrm{R} / \mathrm{W}$ & 1.234 & 1.01 & 1.2 & $\mathrm{H}$ & 1.01 & -186.21 \\
\hline & - & - & - & - & - & L & 1.58 & -153.47 \\
\hline \multirow[t]{2}{*}{ rs370893734 } & 140 & $\mathrm{D} / \mathrm{N}$ & 1.439 & 1.25 & 0.66 & $\mathrm{H}$ & 0.93 & -156.05 \\
\hline & - & - & - & - & - & $L$ & 0.89 & -149.23 \\
\hline \multirow[t]{2}{*}{ rs370893734 } & 140 & $\mathrm{D} / \mathrm{Y}$ & 0.398 & 0.6 & 2.03 & $\mathrm{H}$ & 1.28 & -160.89 \\
\hline & - & - & - & - & - & L & 1.29 & -158.06 \\
\hline \multirow[t]{2}{*}{ rs763621932 } & 141 & $Y / S$ & 0.72 & 0.86 & 0.57 & $\mathrm{H}$ & 1.3 & -180.87 \\
\hline & - & - & - & - & - & $L$ & 1.02 & -148.78 \\
\hline
\end{tabular}

${ }^{a}$ Amino acid positions were calculated excluding the signal peptide (76 amino acids)

${ }^{\mathrm{b}}$ Positive values of $\Delta \Delta \mathrm{G}$ indicate decreasing affinity

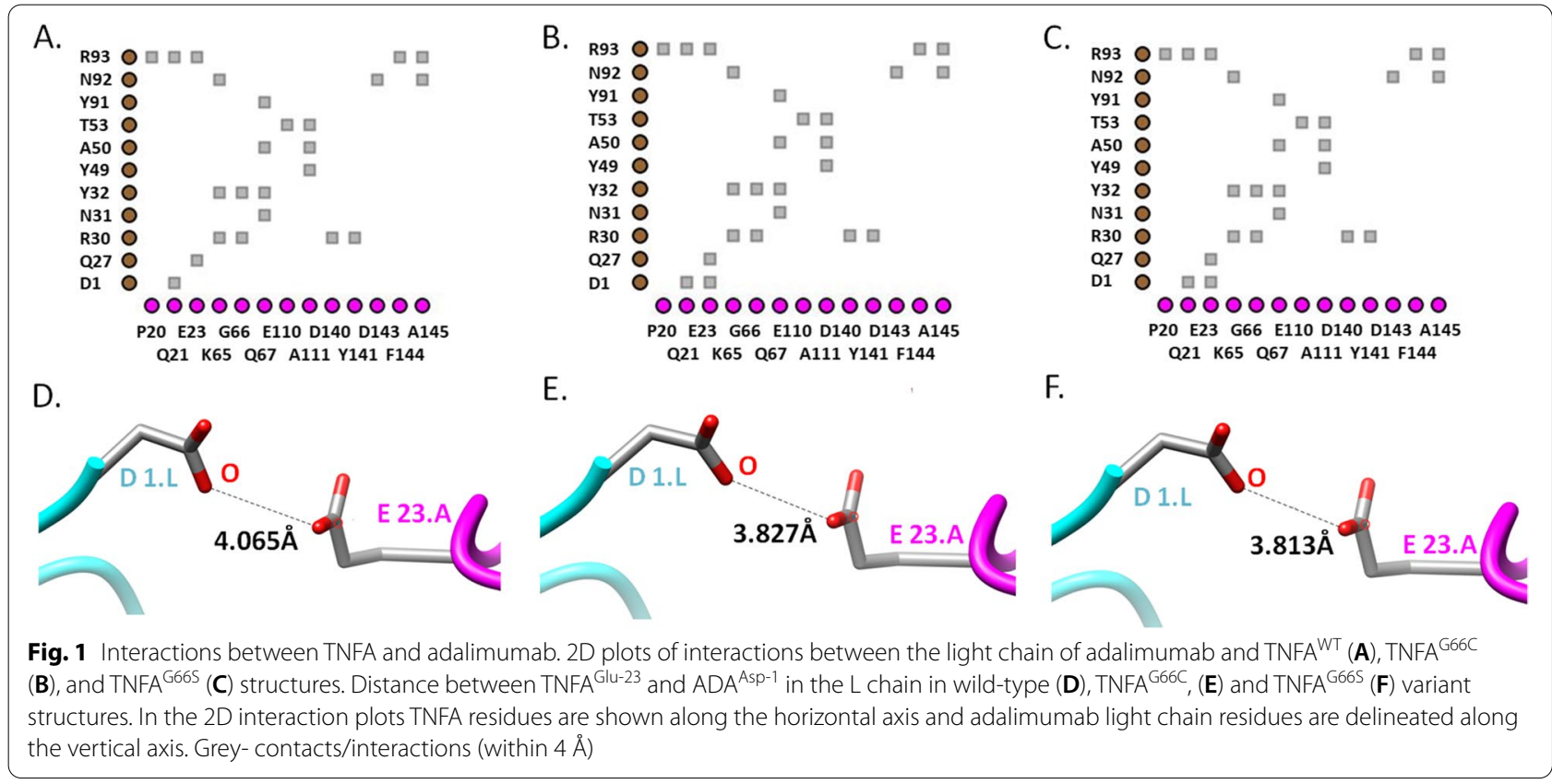


Table 6 Effects of selected variants on TNFA structure and TNFA-mAb interactions

\begin{tabular}{|c|c|c|c|c|c|c|c|c|c|}
\hline \multirow[t]{2}{*}{$\overline{m A b}$} & \multirow[t]{2}{*}{ TNFA variants } & \multirow[t]{2}{*}{ TNFA structural changes } & \multirow[t]{2}{*}{ Ab chain } & \multicolumn{2}{|c|}{ Surface area $\left(\AA^{2}\right)$} & \multicolumn{4}{|c|}{ No. of bonds/interactions } \\
\hline & & & & Total & Buried & van der Waals & H-bonds & $\begin{array}{l}\text { Weak } \\
\text { H-bonds }\end{array}$ & $\begin{array}{l}\text { lonic } \\
\text { interactions }\end{array}$ \\
\hline \multirow[t]{3}{*}{ ADA } & WT & - & L & 18368.58 & 1904.76 & 23 & 27 & 28 & 5 \\
\hline & G66C & Expansion of cavity volume by $74.088 \AA^{3}$ & L & 18382.12 & 2044.42 & 21 & 23 & 31 & 5 \\
\hline & G66S & Expansion of cavity volume by $79.92 \AA^{3}$ & $L$ & 18380.93 & 2040.04 & 22 & 23 & 31 & 5 \\
\hline \multirow[t]{6}{*}{ CZP } & WT & - & $\mathrm{H}$ & 19609.53 & 1285.39 & 32 & 33 & 38 & 5 \\
\hline & WT & - & L & 18577.46 & 1819.46 & 34 & 36 & 36 & 9 \\
\hline & R131Q & No structural damage & $\mathrm{H}$ & 19622.71 & 1284.04 & 33 & 32 & 38 & 5 \\
\hline & E135G & No structural damage & L & 19622.71 & 1800.98 & 35 & 36 & 36 & 9 \\
\hline & $\mathrm{R} 138 \mathrm{Q}$ & No structural damage & $L$ & 18570.75 & 1786.87 & 34 & 36 & 35 & 9 \\
\hline & R138W & No structural damage & $L$ & 18546.29 & 1841 & 34 & 36 & 36 & 9 \\
\hline \multirow[t]{2}{*}{ GLM } & WT & - & $\mathrm{H}$ & 14262.13 & 2020.62 & 21 & 29 & 25 & 10 \\
\hline & Y141S & No structural damage & $\mathrm{H}$ & 14314.38 & 2018.65 & 18 & 29 & 25 & 10 \\
\hline \multirow[t]{2}{*}{ IFX } & WT & - & $L$ & 18788.1 & 1193.27 & 25 & 28 & 39 & 9 \\
\hline & R138W & No structural damage & $\mathrm{L}$ & 18802.43 & 1180.42 & 25 & 28 & 37 & 9 \\
\hline
\end{tabular}

The binding affinity of ADA may be affected by TNFA $^{\text {G66C }}$ and TNFA ${ }^{\text {G66S }}$ variants (Table 2). Although Gly66 in TNFA does not directly interact with any residue of ADA, it is a part of the epitope [20]. Both TNFA $^{\text {G66C }}$ and TNFA ${ }^{\text {G66S }}$ variants brought Glu23 of TNFA in contact with (within $4 \AA$ ) Asp1 of ADA in the L chain (Fig. 1C-F). Glu23 of TNFA contributes considerably to ADA binding [20]. Besides, two flanking residues of Gly66 in TNFA-Lys65 and Gln67-are essential for ADA binding [20]. Hence, the substitution of Gly66 in TNFA is likely to interfere with the binding affinity of ADA. Additionally, TNFA ${ }^{\text {G66C }}$ and TNFA ${ }^{\text {G66S }}$ significantly altered the TNFA structure in complex with ADA (cavity was expanded by $>70 \AA^{3}$ ), but not in its trimeric state (PDB ID: 1TNF). Such changes could affect the stability of TNFA in complex with ADA [39]. These variants also increased the buried surface between TNFA and the L chain of ADA by > $100 \AA^{2}$ and introduced observable changes in the antigen-antibody interface (Fig. $2 \mathrm{~B}$ and C). Although the buried surface area between antigen and antibody may not reveal much information regarding the strength of their interactions [56], changes in such area may provide further evidence of structural alterations by TNFA ${ }^{\mathrm{G} 66 \mathrm{C}}$ and TNFA ${ }^{\mathrm{G} 66 \mathrm{~S}}$. As a result of these alterations, there was weakening and/or losses of van der Waals interactions and $\mathrm{H}$-bonds between TNFA ${ }^{\mathrm{G} 66 \mathrm{C}}$ and TNFA $^{\text {G66S }}$ with the L chain of ADA.

Among the other epitopic missense variant positions, substitution of Glu135 in TNFA with an alanine caused dramatic reduction in TNFA-ADA affinity [20]. But such drastic reduction in presence of TNFA ${ }^{\text {E135G }}$ and TNFA $^{\text {E135K }}$ variants was not observed, which might be due to interaction of ADA with Glu135 in an adjacent TNFA protomer [20].

TNFA $^{\mathrm{R} 131 \mathrm{Q}}$, TNFA ${ }^{\mathrm{E} 135 \mathrm{G}}, \mathrm{TNFA}^{\mathrm{R} 138 \mathrm{Q}}$, and TNFA ${ }^{\mathrm{R} 138 \mathrm{~W}}$ were predicted to affect TNFA-CZP interactions (Table 3). Substitution of Arg138 in TNFA with an Ala drastically decreases binding affinity to CZP [21]. In agreement with this finding, we found that both $\mathrm{TNFA}^{\mathrm{R} 138 \mathrm{Q}}$ and $\mathrm{TNFA}^{\mathrm{R} 138 \mathrm{~W}}$ missense variants at this position may substantially reduce interaction with CZP. We also observed changes in the patterns of interacting residues in the CZP L chain in the case of these two variants (Fig. 4E and F). H-bond between Glu135 of TNFA and Tyr49 of CZP in the L chain plays a supplementary role in the energetics of TNFA-CZP interactions [21]. Although both TNFA ${ }^{\mathrm{E} 135 \mathrm{G}}$ and TNFA ${ }^{\mathrm{E} 135 \mathrm{~K}}$ were predicted to destabilize the TNFA-CZP interactions with majority of the tools, these predictions could not be replicated with the 3D models of the TNFA ${ }^{\text {E135K }}$ variant. Substitution of both Arg138 and Glu135 in TNFA interrupted the formation of $\mathrm{H}$-bonds between these residues and two Tyr residues of CZP (Tyr60 and Tyr49, respectively) in the $\mathrm{L}$ chain (Fig. 2C-E). Interactions between residues in epitopes and Tyr residues in paratopes are extremely important in the context of antigen-antibody affinity [57]. TNFA $^{\text {R131A }}$ does not affect CZP binding affinity [21]. But in our study, TNFA ${ }^{\mathrm{R} 131 \mathrm{Q}}$ was predicted and determined to reduce the affinity of the $\mathrm{H}$ chain of CZP to TNFA in most of the cases as it caused the loss of salt bridge and/ or ionic interaction between Arg131 of TNFA and Asp31 of CZP in the $\mathrm{H}$ chain (Fig. 3A and B). Side-chain atoms (NH1) of Arg131 in TNFA participate in this interaction (detected with iCn3D). So, the substitution of this residue is supposed to eliminate this salt bridge/ionic interaction 
A.

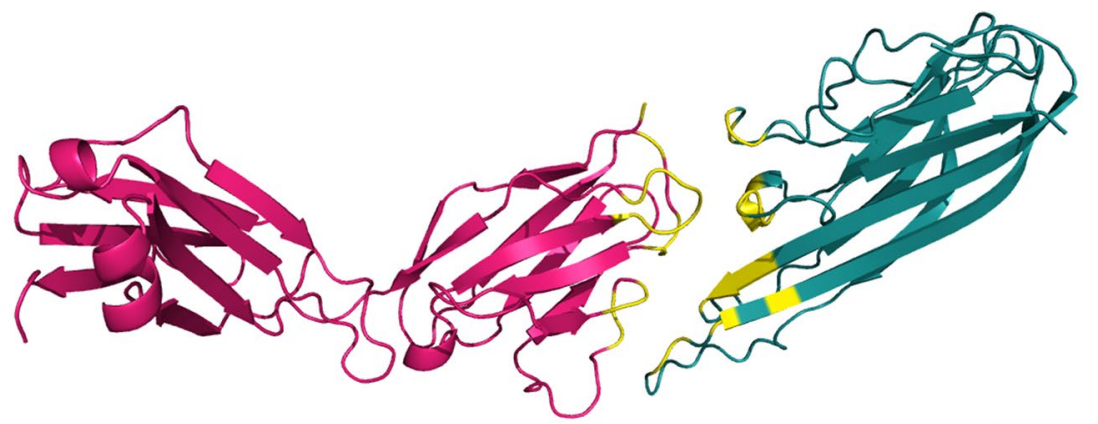

B.
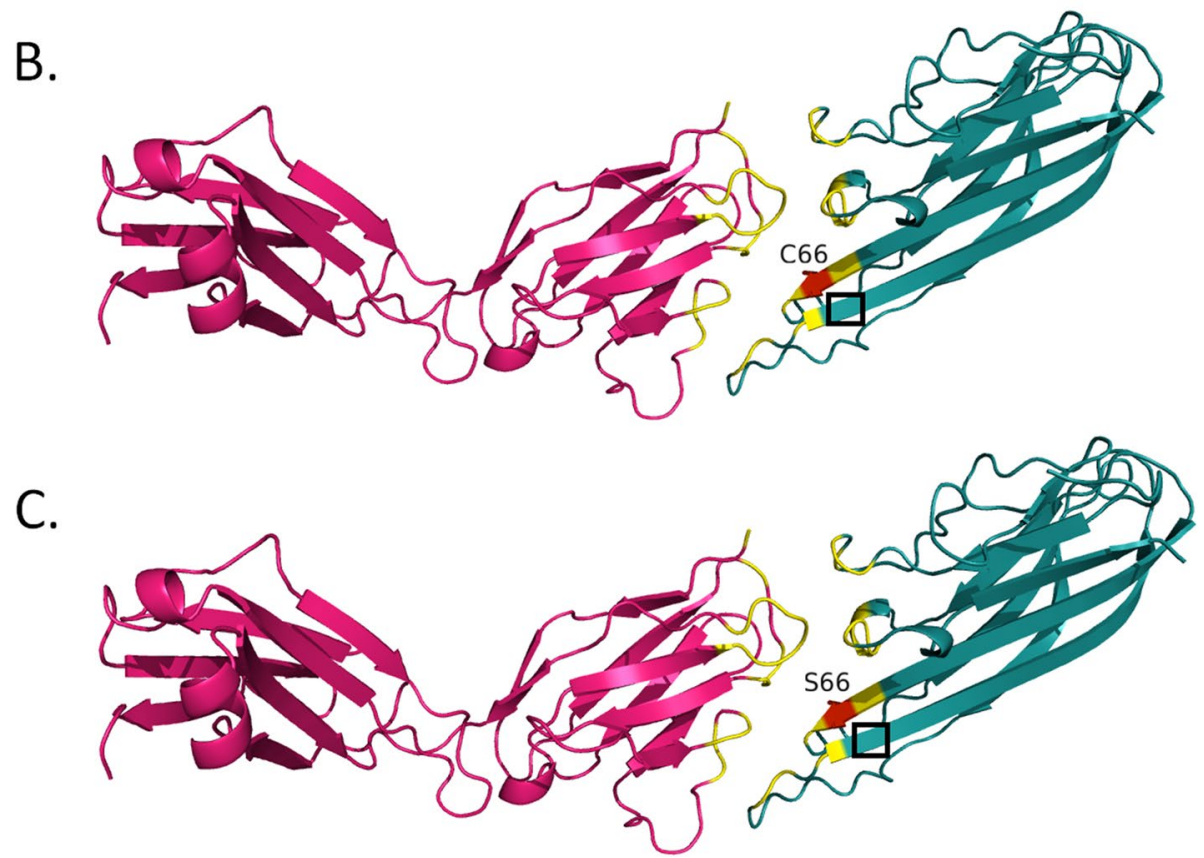

Fig. 2 Interactions between TNFA and adalimumab. Interactions between the light chain of adalimumab and TNFA ${ }^{\mathrm{WT}}(\mathbf{A})$, TNFA ${ }^{\mathrm{G} 66 \mathrm{C}}(\mathbf{B})$, and TNFA $^{6665}(\mathbf{C})$ structures. Hot pink- adalimumab light chain; deep teal-TNFA; yellow- interface; red-mutated residue. Regions with altered antigen-antibody interactions are denoted with black rectangles

with CZP, which may cause structural changes in the antigen-antibody interface (Fig. 4B).

In the present study, TNFA ${ }^{\mathrm{Y} 141 \mathrm{~S}}$ was predicted to significantly destabilize $(\Delta \Delta \mathrm{G}>1.0 \mathrm{kcal} / \mathrm{mol})$ TNFA-GLM interactions by all the tools used (Table 4). This variant reduced the binding affinity of the $\mathrm{H}$ chain of GLM to TNFA. Tyr141 of TNFA forms the H-bond with Tyr110 of GLM in the $\mathrm{H}$ chain (Fig. 3A). TNFA ${ }^{\mathrm{Y} 141 \mathrm{~S}}$ resulted in the loss of this $\mathrm{H}$-bond (Fig. $3 \mathrm{~B}$ ). TNFA ${ }^{\mathrm{R} 138 \mathrm{~W}}$ was predicted to drastically reduce $(\Delta \Delta \mathrm{G}>1.0 \mathrm{Kcal} / \mathrm{mol})$ interaction strength between TNFA and IFX by all predictive tools, but such reductions could not be detected in the 3D models of TNFA-IFX complex (Table 5). TNFA ${ }^{\mathrm{R} 138 \mathrm{~W}}$ caused the loss of cation-pi interaction between Arg131 of TNFA and Phe96 of IFX in the L chain (Fig. 5C and D). Cation-pi interactions play a crucial role in stabilizing antigen-antibody complexes [58].
None of the variants, except TNFA ${ }^{\text {G66C }}$ and TNFA ${ }^{\text {G66S }}$, caused alteration in the TNFA structure in the complex with the corresponding mAbs or changed the buried surface area between TNFA and mAbs (Table 6). Besides, calculations by Arpeggio [41] hardly detected changes in the number of interactions in any other variant except TNFA $^{\text {G66C }}$ and TNFA ${ }^{\text {G66S }}$. So, in the case of TNFA ${ }^{\text {G66C }}$ and $\mathrm{TNFA}^{\mathrm{G} 66 \mathrm{~S}}$, structural alterations and eventual reductions in TNFA-ADA $L$ chain interactions caused a decrease in TNFA-ADA affinity. In the case of the other three mAbs, the losses of some specific interactions (mostly H-bonds) caused reductions in the TNFA-mAb affinity. Another important finding of this study is that TNFA $^{\mathrm{R} 138 \mathrm{~W}}$ may interrupt both TNFA-CZP and TNFAIFX interactions. So, individuals with this variant may be poor responders to both CZP and IFX. Further studies are needed to confirm this prediction. None of these 


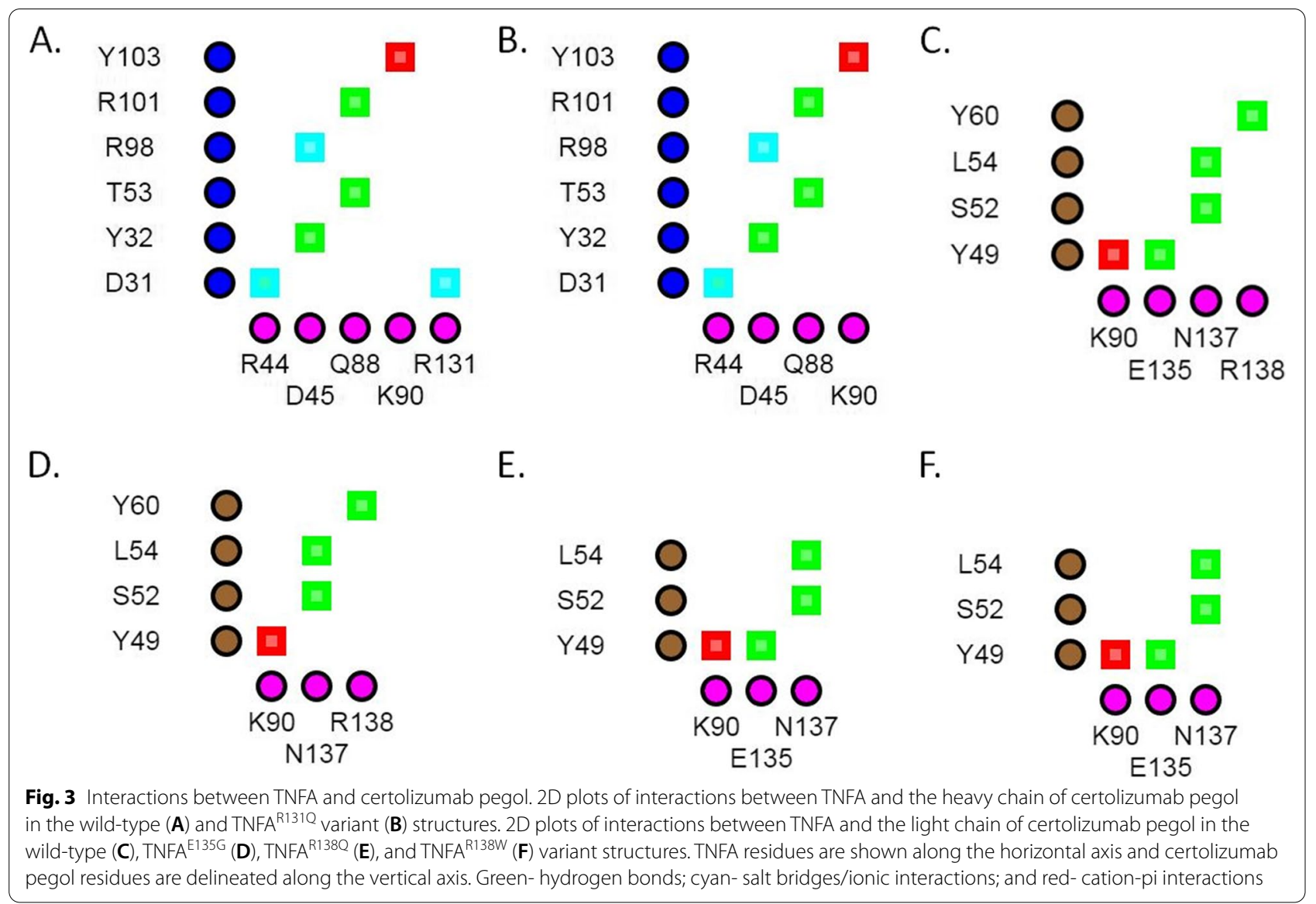

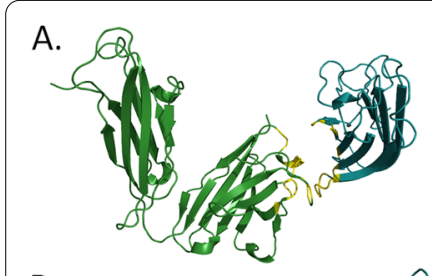

D.

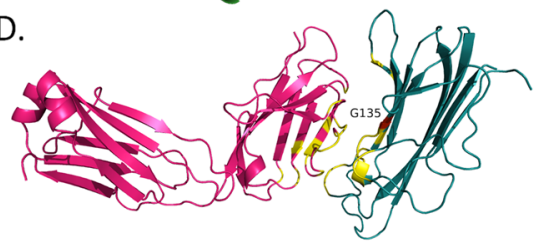

B.

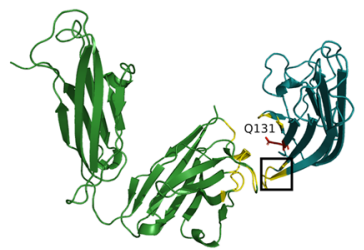

E.

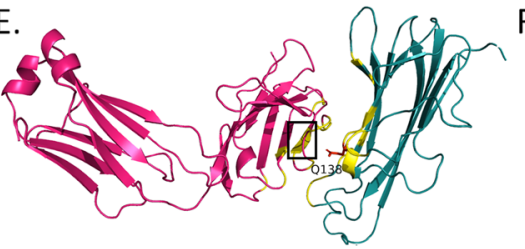

C.

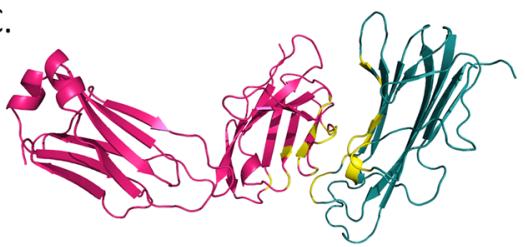

F.

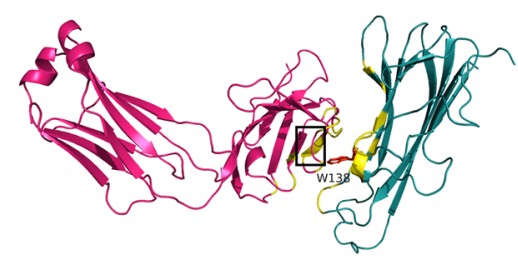

Fig. 4 Interactions between TNFA and certolizumab pegol. Interactions between TNFA and the heavy chain of certolizumab pegol in the wild-type (A) and TNFA ${ }^{\text {R131Q }}$ variant (B) structures. Interactions between TNFA and the light chain of certolizumab pegol in the wild-type (C), TNFA ${ }^{\mathrm{E} 135 \mathrm{G}}$ (D), $\operatorname{TNFA}^{\mathrm{R} 138 \mathrm{Q}}(\mathbf{E})$, and TNFA ${ }^{\mathrm{R} 138 \mathrm{~W}}(\mathbf{F})$ variant structures. Forest green- heavy chain of certolizumab pegol; hot pink-, light chain of certolizumab pegol; deep teal-TNFA; yellow- interface; red- mutated residue. Regions with altered antigen-antibody interactions are denoted with black rectangles

variants affect the distribution of the TNFA residues that play important role in TNFA-TNFR2 interactions $[20,59]$. So, these variants are less likely to affect interactions between TNFA and its receptor. This assumption was confirmed using predictive tools (Supplementary Table 1).

The seven missense variants $\left(\mathrm{TNFA}^{\mathrm{G} 66 \mathrm{C}}\right.$, TNFA ${ }^{\mathrm{G} 66 \mathrm{~S}}$, $\mathrm{TNFA}^{\mathrm{R} 131 \mathrm{Q}}, \mathrm{TNFA}^{\mathrm{E} 135 \mathrm{G}}, \mathrm{TNFA}^{\mathrm{R} 138 \mathrm{Q}}, \mathrm{TNFA}^{\mathrm{R} 138 \mathrm{~W}}$, and 

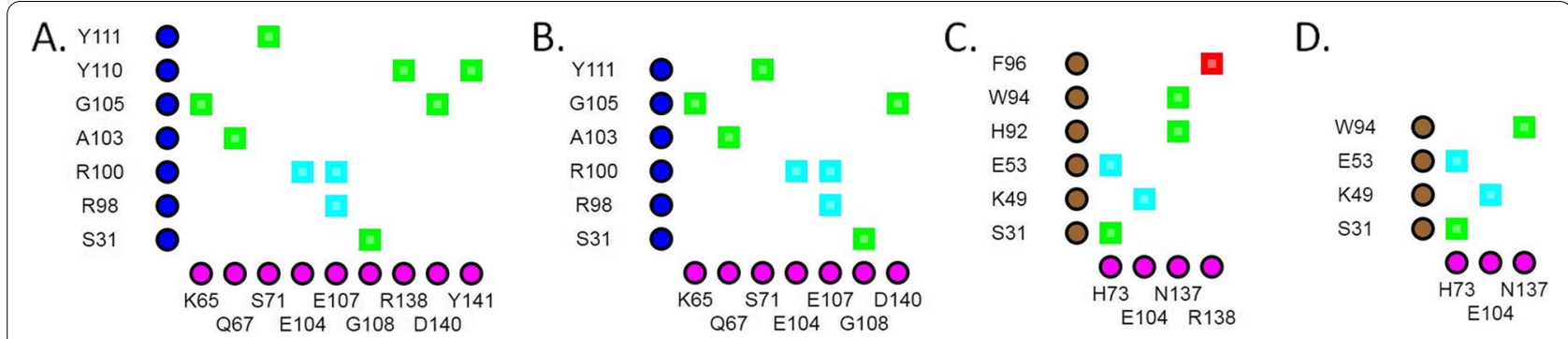

Fig. 5 Interactions of TNFA with golimumab and infliximab. 2D plots of interactions between TNFA and the heavy chain of golimumab in the wild-type (A) and TNFA ${ }^{Y 141 S}$ variant (B) structures. 2D plots of interactions between TNFA and the light chain of infliximab in the wild-type (C) and TNFA $^{\text {R138W }}$ variant (D) structures. TNFA residues are shown along the horizontal axis and antibody residues are delineated along the vertical axis. Green- hydrogen bonds; cyan- salt bridges/ionic interactions; and red-cation-pi interactions

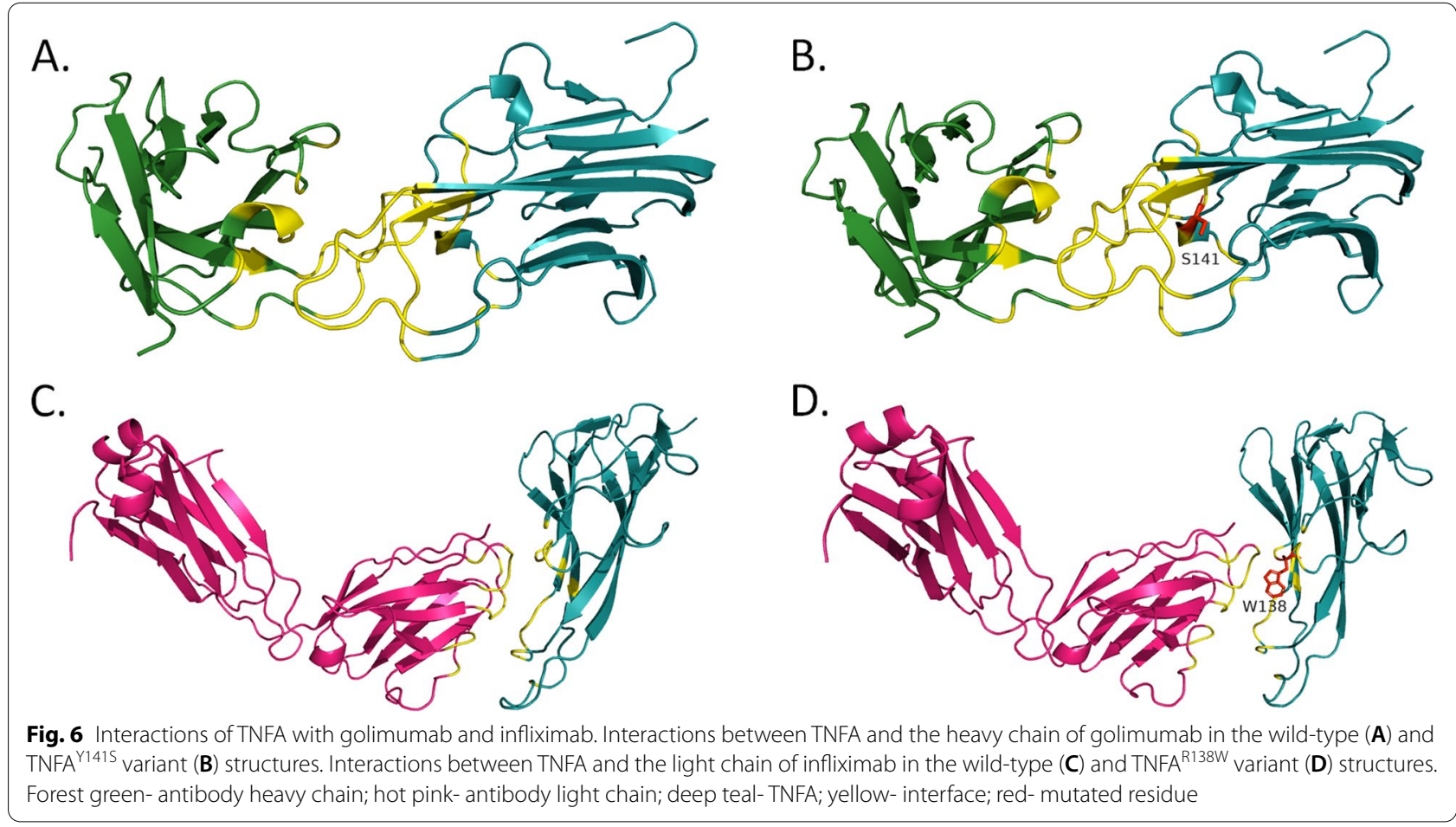

Table 7 Predicted pathogenicity of the selected variants

\begin{tabular}{|c|c|c|c|c|c|}
\hline Variants & SIFT_Class & Polyphen_Class & PMut & Meta-SNP & PredictSNP1.0 \\
\hline TNFA ${ }^{\mathrm{G} 66 \mathrm{C}}$ & Deleterious & Probably damaging & Disease & Disease & Deleterious \\
\hline TNFA ${ }^{\mathrm{G} 66 \mathrm{~S}}$ & Deleterious & Possibly damaging & Disease & Disease & Deleterious \\
\hline TNFA $^{\text {R131Q }}$ & Tolerated & Benign & Neutral & Neutral & Neutral \\
\hline TNFA $^{E 135 G}$ & Deleterious & Possibly damaging & Disease & Disease & Deleterious \\
\hline TNFA $^{\text {R138Q }}$ & Tolerated & Benign & Neutral & Neutral & Neutral \\
\hline TNFA $^{\mathrm{R} 138 \mathrm{~W}}$ & Tolerated & Possibly damaging & Neutral & Neutral & Deleterious \\
\hline TNFA $^{Y 141 S}$ & Deleterious & Benign & Disease & Neutral & Deleterious \\
\hline
\end{tabular}


TNFA $^{\mathrm{Y} 141 \mathrm{~S}}$ ) are present at low frequencies in the global population. TNFA ${ }^{\mathrm{G} 66 \mathrm{C}}$ and TNFA ${ }^{\mathrm{G} 66 \mathrm{~S}}$, however, may be associated with autoimmune disease [51]. TNFA ${ }^{\mathrm{E} 135 \mathrm{G}}$ was predicted to be pathogenic by all the tools used in this analysis (Table 7). Among these tools, SIFT uses sequence homology to predict the effect of an amino acid substitution on protein function [60]. PolyPhen2 uses multiple protein sequence alignment pipeline and machine learning classification method to predict a missense variant's pathogenicity [61]. PMut also uses the machine learning method [46]. Meta-SNP and Predict SNP 1.0 are consensus classifiers that utilize results from multiple high-performing classifier tools $[47,48]$. So, it is highly probable that TNFA ${ }^{\mathrm{E} 135 \mathrm{G}}$ may be associated with disease. Besides, TNFA ${ }^{\mathrm{R} 138 \mathrm{~W}}$ and TNFA ${ }^{\mathrm{Y} 141 \mathrm{~S}}$ were predicted to be disease-causing by multiple tools. Further studies are needed to clarify if these three variants are associated with autoimmune diseases that are treated with anti-TNFA mAbs. If so, then at least these three variants along with TNFA ${ }^{\text {G66C }}$ and TNFA ${ }^{\text {G66S }}$ can be more frequent among patients who are treated with anti-TNFA mAbs compared with the rest of the population.

In order to contextualize our findings, we searched for ADA, CZP, GLM, and IFX response-associated SNPs in the Pharmacogenomics Knowledge Base (PharmGKB) [62]. We found twenty-one ADA, CZP, and IFX responserelated SNPs. No GLM response-associated SNP was found. All these variant-drug combinations have level 3 clinical annotation, i.e., evidence for those associations comes from single significant studies and the findings are yet to be replicated [62]. Variant alleles of these SNPs may be associated with poor [63] or better response [64]. The response may also depend on the disease being treated [65]. Only two (rs1799724 and rs361525) of these 21 SNPs were located in the TNF gene. rs1799724 and rs361525 are both located in the non-coding region and associated with responses to ADA [66] and IFX [67] in rheumatoid arthritis patients, respectively. So, there is a huge gap in our knowledge regarding the roles played by anti-TNFA mAb response-associated SNPs in their therapeutic outcome. Our study identifies seven missense variants in the epitopic region of TNFA, which may be predictive of the clinical outcomes of anti-TNFA mAb therapy regardless of the disease being treated. Moreover, this is the first study to our knowledge that has identified an association between a probable disease-causing variant $\left(\mathrm{TNFA}^{\mathrm{Y} 141 \mathrm{~S}}\right)$ and response to GLM. Therefore, our findings may contribute to the further clarification of the roles played by patients' genotypes in their responses to ADA, CZP, GLM, and IFX.

\section{Conclusion}

This study was inspired by the high rate $(30-40 \%)$ of non-responsiveness to therapeutic anti-TNFA antibodies, which are used to treat multiple debilitating autoimmune diseases like rheumatoid arthritis, Crohn's disease, ulcerative colitis, psoriasis, psoriatic arthritis, and ankylosing spondylitis. This in silico study predicts the candidate genetic variants that may underlie such variable responses to anti-TNFA antibodies. Based on these predictions, further studies may be designed and conducted using in vitro models to assess the effects of candidate variants on TNFA-mAb interactions. In addition, studies with patients undergoing treatments with anti-TNFA antibodies may shed more light on this heterogeneous responsiveness. Determining the genotypes at the candidate variant loci may improve clinical outcomes in patients. Also, population-specific studies might highlight the general genetic architecture at these loci, and thus help decide the more appropriate therapeutic antibodies for treatment.

\section{Abbreviations}

TNFA: Tumor necrosis factor alpha; mAb: Monoclonal antibody; ADA: Adalimumab; CZP: Certolizumab pegol; GLM: Golimumab; IFX: Infliximab; SNP: Single-nucleotide polymorphism.

\section{Supplementary Information}

The online version contains supplementary material available at https://doi. org/10.1186/s43141-021-00288-y.

Additional file 1: Supplementary Table 1. Effects of missense variants on TNFA-TNFR2 interactions.

\section{Acknowledgements}

This study was supported by a grant from the Ministry of Health and Family Welfare, Bangladesh to AAS. The authors are thankful for the support.

\section{Authors' contributions}

TA: Methodology, acquisition, analysis, and interpretation of data; manuscript preparation and reviewing. AAS: Conceptualization, acquisition, analysis, and interpretation of data; manuscript preparation and reviewing. The authors read and approved the final manuscript.

\section{Funding}

Ministry of Health and Family Welfare, Bangladesh.

Availability of data and materials

All data generated or analyzed during this study are included in this published article (and its supplementary information files).

\section{Declarations}

Ethics approval and consent to participate

This study neither involved any human or animal, and hence, no ethical approval was required.

Consent for publication

This study did not involve any human and personal data (any individual details, images, or videos)), and hence, no consent for publication was required. 


\section{Competing interests}

The authors have no conflict of interest to declare.

\section{Author details}

'Molecular Biotechnology Division, National Institute of Biotechnology, Dhaka 1349, Bangladesh. ${ }^{2}$ Department of Genetic Engineering \& Biotechnology, University of Dhaka, Dhaka 1000, Bangladesh.

Received: 10 September 2021 Accepted: 13 December 2021 Published online: 10 January 2022

\section{References}

1. MacEwan DJ (2002) TNF receptor subtype signalling: differences and cellular consequences. Cell Signal. 14:477-492

2. Kalliolias GD, Ivashkiv LB (2016) TNF biology, pathogenic mechanisms and emerging therapeutic strategies. Nat Rev Rheumatol. 12:49-62

3. Wajant H, Pfizenmaier K, Scheurich P (2003) Tumor necrosis factor signaling. Cell Death Differ. 10:45-65

4. Loetscher H, Pan YC, Lahm HW, Gentz R, Brockhaus M, Tabuchi H et al (1990) Molecular cloning and expression of the human $55 \mathrm{kd}$ tumor necrosis factor receptor. Cell. 61:351-359

5. Grell M, Wajant H, Zimmermann G, Scheurich P (1998) The type 1 receptor (CD120a) is the high-affinity receptor for soluble tumor necrosis factor. Proc Natl Acad Sci U S A. 95:570-575

6. Kanehisa M, Goto S (2000) KEGG: Kyoto encyclopedia of genes and genomes. Nucleic Acids Res 28:27-30. https://doi.org/10.1093/nar/28.1.27

7. Wajant H, Siegmund D (2019) TNFR1 and TNFR2 in the control of the life and death balance of macrophages. Front Cell Dev Biol. 7:91

8. Pan S, An P, Zhang R, He X, Yin G, Min W (2002) Etk/Bmx as a tumor necrosis factor receptor type 2-specific kinase: role in endothelial cell migration and angiogenesis. Mol Cell Biol. 22:7512-7523

9. Yang S, Wang J, Brand DD, Zheng SG (2018) Role of TNF-TNF receptor 2 signal in regulatory $T$ cells and its therapeutic implications. Front Immunol. 9:784

10. Naudé PJW, den Boer JA, Luiten PGM, Eisel ULM (2011) Tumor necrosis factor receptor cross-talk. FEBS J. 278:888-898

11. Chu W-M (2013) Tumor necrosis factor. Cancer Lett. 328:222-225

12. Gorman JD, Sack KE, Davis JC (2002) Treatment of ankylosing spondylitis by inhibition of tumor necrosis factor a. N Engl J Med. 346:1349-1356

13. Mease PJ (2002) Tumour necrosis factor (TNF) in psoriatic arthritis: pathophysiology and treatment with TNF inhibitors. Ann Rheum Dis. 61:298-304

14. Ware CF (2013) Protein therapeutics targeted at the TNF superfamily. Adv Pharmacol. 66:51-80

15. Wishart DS, Feunang YD, Guo AC, Lo EJ, Marcu A, Grant JR et al (2018) DrugBank 5.0: a major update to the DrugBank database for 2018. Nucleic Acids Res. 46:D1074-D1082

16. Mease PJ (2007) Adalimumab in the treatment of arthritis. Ther Clin Risk Manag. 3:133-148

17. Acosta-Felquer ML, Rosa J, Soriano ER (2016) An evidence-based review of certolizumab pegol in the treatment of active psoriatic arthritis: place in therapy. Open Access Rheumatol Res Rev. 8:37-44

18. Mazumdar S, Greenwald D (2009) Golimumab. MAbs 1:422-431

19. Klotz U, Teml A, Schwab M (2007) Clinical pharmacokinetics and use of infliximab. Clin Pharmacokinet. 46:645-660

20. Hu S, Liang S, Guo H, Zhang D, Li H, Wang X et al (2013) Comparison of the inhibition mechanisms of adalimumab and infliximab in treating tumor necrosis factor a-associated diseases from a molecular view. J Biol Chem. 288:27059-27067

21. Lee JU, Shin W, Son JY, Yoo K-Y, Heo Y-S (2017) Molecular basis for the neutralization of tumor necrosis factor a by certolizumab pegol in the treatment of inflammatory autoimmune diseases. Int J Mol Sci. 18:228

22. Ono M, Horita S, Sato Y, Nomura Y, I wata S, Nomura N (2018) Structural basis for tumor necrosis factor blockade with the therapeutic antibody golimumab. Protein Sci. 27:1038-1046

23. Liang S, Dai J, Hou S, Su L, Zhang D, Guo H et al (2013) Structural basis for treating tumor necrosis factor a (TNFa)-associated diseases with the therapeutic antibody infliximab. J Biol Chem. 288:13799-13807
24. Lu R-M, Hwang Y-C, Liu I-J, Lee C-C, Tsai H-Z, Li H-J et al (2020) Development of therapeutic antibodies for the treatment of diseases. J Biomed Sci. 27:1

25. Bonafede MMK, Gandra SR, Watson C, Princic N, Fox KM (2012) Cost per treated patient for etanercept, adalimumab, and infliximab across adult indications: a claims analysis. Adv Ther. 29:234-248

26. Said C, Coleiro B, Zarb Adami M, Azzopardi LM, Serracino Inglott A (2013) Cost effectiveness of TNF-a inhibitors in rheumatoid arthritis. Int J Inflam. 2013:1-8

27. Menegatti S, Bianchi E, Rogge L (2019) Anti-TNF therapy in spondyloarthritis and related diseases, impact on the immune system and prediction of treatment responses. Front Immunol. 10:382

28. Bongartz T, Sutton AJ, Sweeting MJ, Buchan I, Matteson EL, Montori V (2006) Anti-TNF antibody therapy in rheumatoid arthritis and the risk of serious infections and malignancies: systematic review and metaanalysis of rare harmful effects in randomized controlled trials. JAMA. 295:2275-2285

29. Yates AD, Achuthan P, Akanni W, Allen J, Allen J, Alvarez-Jarreta J et al (2020) Ensembl 2020. Nucleic Acids Res 48:D682-D688

30. Berman HM, Westbrook J, Feng Z, Gilliland G, Bhat TN, Weissig $\mathrm{H}$ et al (2000) The protein data bank. Nucleic Acids Res. 28:235-242

31. Pettersen EF, Goddard TD, Huang CC, Couch GS, Greenblatt DM, Meng EC et al (2004) UCSF Chimera--a visualization system for exploratory research and analysis. J Comput Chem. 25:1605-1612

32. Rodrigues CHM, Myung Y, Pires DE V, Ascher DB (2019) mCSM-PPI2: predicting the effects of mutations on protein-protein interactions. Nucleic Acids Res. 47:W338-W344

33. Pahari S, Li G, Murthy AK, Liang S, Fragoza R, Yu H et al (2020) SAAMBE-3D predicting effect of mutations on protein-protein interactions. Int J Mol Sci. 21:2563

34. Li M, Simonetti FL, Goncearenco A, Panchenko AR (2016) MutaBind estimates and interprets the effects of sequence variants on protein-protein interactions. Nucleic Acids Res. 44:W494-W501

35. UniProt Consortium T (2018) UniProt: the universal protein knowledgebase. Nucleic Acids Res. 46:2699-2699

36. Raybould MIJ, Marks C, Lewis AP, Shi J, Bujotzek A, Taddese B et al (2020) Thera-SAbDab: the therapeutic structural antibody database. Nucleic Acids Res 48:D383-D388

37. Waterhouse A, Bertoni M, Bienert S, Studer G, Tauriello G, Gumienny R et al (2018) SWISS-MODEL: homology modelling of protein structures and complexes. Nucleic Acids Res. 46:W296-W303

38. Sukhwal A, Sowdhamini R (2015) PPCheck: a webserver for the quantitative analysis of protein-protein interfaces and prediction of residue hotspots. Bioinform Biol Insights. 9:141-151

39. Ittisoponpisan S, Islam SA, Khanna T, Alhuzimi E, David A, Sternberg MJE (2019) Can predicted protein 3D structures provide reliable insights into whether missense variants are disease associated? J Mol Biol. 431:2197-2212

40. Wang J, Youkharibache P, Zhang D, Lanczycki CJ, Geer RC, Madej T et al (2020) iCn3D, a web-based 3D viewer for sharing 1D/2D/3D representations of biomolecular structures. Bioinformatics. 36:131-135

41. Jubb HC, Higueruelo AP, Ochoa-Montaño B, Pitt WR, Ascher DB, Blundell TL (2017) Arpeggio: a web server for calculating and visualising interatomic interactions in protein structures. J Mol Biol. 429:365-371

42. Schrödinger $L$, DeLano W (2020) PyMOL. http://www.pymol.org/pymol.

43. Zhang N, Chen Y, Lu H, Zhao F, Alvarez RV, Goncearenco A et al (2020) MutaBind2: predicting the impacts of single and multiple mutations on protein-protein interactions. IScience. 23:100939

44. Piñero J, Ramírez-Anguita JM, Saüch-Pitarch J, Ronzano F, Centeno E, Sanz F et al (2020) The DisGeNET knowledge platform for disease genomics: 2019 update. Nucleic Acids Res. 48:D845-D855

45. Kamat MA, Blackshaw JA, Young R, Surendran P, Burgess S, Danesh J et al (2019) PhenoScanner V2: an expanded tool for searching human genotype-phenotype associations. Bioinformatics. 35:4851-4853

46. López-Ferrando V, Gazzo A, de la Cruz X, Orozco M, Gelpí JL (2017) PMut: a web-based tool for the annotation of pathological variants on proteins, 2017 update. Nucleic Acids Res. 45:W222-W228

47. Capriotti E, Altman RB, Bromberg Y (2013) Collective judgment predicts disease-associated single nucleotide variants. BMC Genomics. 14(Suppl 3):S2 
48. Bendl J, Stourac J, Salanda O, Pavelka A, Wieben ED, Zendulka J et al (2014) PredictSNP: robust and accurate consensus classifier for prediction of disease-related mutations. PLoS Comput Biol. 10:e1003440

49. Brender JR, Zhang Y (2015) Predicting the effect of mutations on proteinprotein binding interactions through structure-based interface profiles. PLoS Comput Biol. 11:e1004494

50. Sirin S, Apgar JR, Bennett EM, Keating AE (2016) AB-Bind: antibody binding mutational database for computational affinity predictions. Protein Sci. 25:393-409

51. Jordan CT, Cao L, Roberson EDO, Duan S, Helms CA, Nair RP et al (2012) Rare and common variants in CARD14, encoding an epidermal regulator of NF-kappaB, in psoriasis. Am J Hum Genet. 90:796-808

52. Pires DEV, Ascher DB, Blundell TL (2014) mCSM: predicting the effects of mutations in proteins using graph-based signatures. Bioinformatics. 30:335-342

53. Gyulkhandanyan A, Rezaie AR, Roumenina L, Lagarde N, Fremeaux-Bacchi V, Miteva MA et al (2020) Analysis of protein missense alterations by combining sequence- and structure-based methods. Mol Genet Genomic Med. 8(4):e1166

54. Nguyen MN, Pradhan MR, Verma C, Zhong P (2017) The interfacial character of antibody paratopes: analysis of antibody-antigen structures. Bioinformatics. 33:2971-2976

55. J Brea-Fernandez A, Ferro M, Fernandez-Rozadilla C, Blanco A, Fachal L, Santamarina M et al (2011) An update of in silico tools for the prediction of pathogenesis in missense variants. Curr Bioinform. 6:185-198

56. Erijman A, Rosenthal E, Shifman JM (2014) How structure defines affinity in protein-protein interactions. PLoS One. 9:e110085

57. Peng H-P, Lee KH, Jian J-W, Yang A-S (2014) Origins of specificity and affinity in antibody-protein interactions. Proc Natl Acad Sci U S A. 111:E2656-E2665

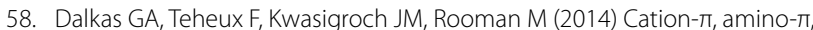
$\pi-\pi$, and $\mathrm{H}$-bond interactions stabilize antigen-antibody interfaces. Proteins. 82:1734-1746

59. Mukai Y, Nakamura T, Yoshikawa M, Yoshioka Y, Tsunoda S, Nakagawa Set al (2010) Solution of the structure of the TNF-TNFR2 complex. Sci Signal. 3(ra83)

60. Ng PC, Henikoff S (2003) SIFT: Predicting amino acid changes that affect protein function. Nucleic Acids Res. 31:3812-3814

61. Adzhubei IA, Schmidt S, Peshkin L, Ramensky VE, Gerasimova A, Bork $P$ et al (2010) A method and server for predicting damaging missense mutations. Nat Methods 7:248-249

62. Whirl-Carrillo M, McDonagh EM, Hebert JM, Gong L, Sangkuhl K, Thorn CF et al (2012) Pharmacogenomics knowledge for personalized medicine. Clin Pharmacol Ther. 92:414-417

63. Montes A, Perez-Pampin E, Narváez J, Cañete JD, Navarro-Sarabia F, Moreira $V$ et al (2014) Association of FCGR2A with the response to infliximab treatment of patients with rheumatoid arthritis. Pharmacogenet Genomics. 24:238-245

64. Koder S, Repnik K, Ferkolj I, Pernat C, Skok P, Weersma RK et al (2015) Genetic polymorphism in ATG16L1 gene influences the response to adalimumab in Crohn's disease patients. Pharmacogenomics. 16:191-204

65. Morales-Lara MJ, Cañete JD, Torres-Moreno D, Hernández MV, Pedrero F, Celis R et al (2012) Effects of polymorphisms in TRAILR1 and TNFR1A on the response to anti-TNF therapies in patients with rheumatoid and psoriatic arthritis. Jt Bone Spine. 279:591-596

66. Miceli-Richard C, Comets E, Verstuyft C, Tamouza R, Loiseau P, Ravaud $P$ et al (2008) A single tumour necrosis factor haplotype influences the response to adalimumab in rheumatoid arthritis. Ann Rheum Dis. 67:478-484

67. Maxwell JR, Potter C, Hyrich KL, Biologics in Rheumatoid Arthritis Genetics and Genomics Study Syndicate, Barton A, Worthington J et al (2008) Association of the tumour necrosis factor-308 variant with differential response to anti-TNF agents in the treatment of rheumatoid arthritis. Hum Mol Genet. 17:3532-3538

\section{Publisher's Note}

Springer Nature remains neutral with regard to jurisdictional claims in published maps and institutional affiliations.

\section{Submit your manuscript to a SpringerOpen ${ }^{\circ}$ journal and benefit from:}

- Convenient online submission

- Rigorous peer review

- Open access: articles freely available online

- High visibility within the field

- Retaining the copyright to your article

Submit your next manuscript at $\gg$ springeropen.com 